\title{
4 \\ Transparency as an Instrumental Value
}

\author{
DAVID HEALD
}

\section{INTRODUCTION}

WHEREAS CHAPTER 2 OF THIS BOOK analysed directions and varieties of transparency, this chapter addresses a single question. Is transparency to be valued intrinsically or instrumentally, or both? Put differently, is transparency a core concern or is it a building block for other valued objects sought by public policy? There is not necessarily a single answer to this question, but posing it will make it easier to assess the contemporary claims made in the name of transparency.

This chapter argues that transparency should be valued instrumentally, and that attempts to elevate it to instrinsic value should be resisted. It proceeds on the basis that transparency - the sunlight metaphorbrings great benefits to economies, governments, and societies. However, as Chapter 2 demonstrated, there has to be sophistication about directions and varieties of transparency and also subtlety about the specific habitats within which they are situated. In general terms, at very low levels of transparency, more transparency is likely to be beneficial. The trade-offs are most apparent when transparency is already high, in which circumstance the direction and variety, not just the amount, of the incremental transparency will strongly influence the relationship between benefits and costs.

\section{POTENTIAL TRADE-OFFS AND SYNERGIES}

It is useful to conceptualize transparency as a set of contested relationships with other objects that themselves may be valued intrinsically and/or instrumentally. Because of non-linearities, these contested relationships are sometimes trade-offs (one must be sacrificed to gain more of the other) and sometimes synergies (more can be gained of each). 
Although other lists of valued objects might have been made, the tradeoffs considered here relate to: effectiveness; trust; accountability; autonomy and control; confidentiality, privacy, and anonymity; fairness; and legitimacy.

There are two distinct literatures that suggest reasons why there might be limits to beneficial transparency. The first generates the proposition that there may be an optimal level of transparency that is less than maximum transparency. This kind of theorizing reflects the influence of economists' approaches to the analysis of social and political issues. Heald (2003: 725-9) represented this view as the working out of the tradeoff between the value of sunlight and the danger of over-exposure. Arguably, the greater the level of transparency, the steeper these trade-offs become. A linked issue concerns the resource and compliance costs of transparency that need to be considered within this optimizing framework of analysis.

The second is a sociological view, propounded by Moore and Tumin (1949: 788-94), that ignorance (imperfect dissemination of existing knowledge or lack of transparency in today's terminology) may contribute positively to social functioning (Hood 2001: 703-4). Their enumeration of such functions is neutral as to whether the effect is benign or malign, with the purpose being to show that efforts to eliminate ignorance may have complex effects, some of which may be unintended and unwanted. Moore and Tumin identified a set of 'social functions of ignorance', some of which now seem dated, though others still resonate, including those relating to the operation of bureaucracies. A lack of transparency may be one of the pillars of pre-established social orders, whether religious or secular, whose sweeping away may have unpredictable effects. Such an order may now have shaky foundations, for example being based on myths that are no longer sustainable if openly challenged. A lack of transparency may avoid jealousy over unequal rewards. Transparency of salaries in the public sector might discourage applicants as the same does not apply for most working in the private sector, where media coverage is generally less intrusive and hostile. Conflict resolution in divided communities may only be achievable when there are differentiated messages to each constituency; managing down conflict in Northern Ireland is a good example of where recourse to differentiated messages is not just hypocrisy. Lloyd (2004: 31-4) cited the case of Gillian Tett, a Financial Times journalist working in Tokyo, who was caught up in the desire of a Japanese corporation to manage dual lines of communication to foreign and domestic audiences, without realizing that a 
message sent out in her world might bounce back to its own. Some measure of dissimulation can be a characteristic of bargaining games; the traditional example is the trade union leader condemning a pay offer as inadequate whilst selling it to the membership. In many spheres, technological change has severely limited the possibility of exploiting dual lines of communication to manage different stakeholders.

In many ways, the sociological view can be interpreted as suggesting reasons why the economists' trade-offs arise. The optimal level of transparency might be regarded as the result of the trade-off between transparency and the seven other objects; these are now briefly examined in turn.

First, transparency can be counterpoised with effectiveness; the relationship is generally perceived to be positive (limiting corruption and malfunctioning of markets, whether financial or product markets) (Vickers 2002: 8-14), but that might have limits ('excessive' or the 'wrong kind' of transparency disrupts organizational functioning). There is the notion that transparency is positively connected to performance, primarily because exposure to public view is presumed to act as a stimulus. However, transparency about operational aspects of process (see Chapter 2) can affect behaviour in unanticipated ways. A famous university destroys exam scripts soon after the examination to prevent student access and disclosure. This defensive behaviour destroys the evidence base on which the path of standards over time might be monitored. Resourceintensive blind double-marking, which enhances reliability but exposes examiners to media ridicule, may be abandoned as too risky. Similarly, potential disclosure of job references or assessments is likely to make them bland, and perhaps encourage 'forgetfulness' on the part of those asked to supply them.

Whilst parliamentary scrutiny of the executive has eroded, public policy decisions now have to be taken under the constant gaze of continuous news and media comment. Policy formulation in public-and measured challenging of policy proposals - has become more difficult because of the inability (reduction in the number of specialist correspondents) and/or unwillingness (competitive pressures and ideological positioning) of much of the media to analyse policy issues seriously. This hampers rational policy-making by making the process vulnerable to interest groups oversimplifying complex issues and to opposition politicians jumping on populist bandwagons. Even the remaining specialist correspondents with accumulated sectoral knowledge face pressure for 'exclusives', which may mean becoming the conduit for government 
plants or leaks by disaffected employees. A likely result is that real policymaking shifts backwards into secret confines, with proposals less subject to challenge (knowledgeable persons/organizations are excluded) and poorly documented (less is written so that less can be leaked and working documents are later shredded or deleted). The 'wrong' varieties of transparency (Prat 2005: 863-4) may encourage conformity to expectation, such as herd-like behaviour in financial markets (Persaud 2000: 1), thus making the net effect on effectiveness difficult to predict.

Second, transparency can be counterpoised with trust, a term in even greater current usage than transparency. Trust is conventionally viewed as an essential component of social capital. In the transparency literature focusing on fiscal and monetary issues, transparency is expected to contribute positively to trust by building credibility (Alt and Lassen 2006). For example, the fact that budget numbers and monetary rules are documented in the public domain reduces the cost of capital to private actors (Glennerster and Shin 2003: 4-7, 30-6). Decision-making benefits would also be expected for national economies and for public organizations. In contrast, O'Neill's Reith Lectures (2002: 63-79) emphasized the damage that transparency can inflict on trust, particularly through the undermining of professional judgement. O'Neill is generally negative about transparency, proposing that, to enhance trust, the objective should be to reduce deception and lies rather than to embrace transparency. Whilst O'Neill's negative view of transparency runs against the overall argument of this chapter, one passage resonates:

Increasing transparency can produce a flood of unsorted information and misinformation that provides little but confusion unless it can be sorted and assessed. It may add to uncertainty rather than to trust ... Transparency can encourage people to be less honest, so increasing deception and reducing reasons for trust; those that know that everything that they say or write is to be made public may massage the truth. (O’Neill 2002: 72-3)

Finel and Lord (1999: 319-22) make a similar point, in connection with why certain but not all international crises lead to war. They distinguish between information availability and information assessment, the latter requiring processing capacity held by external receptors (see also Chapter 2 of this volume). Nor can it be safely assumed that better information will lead to more satisfaction or higher trust; not least, it may suddenly expose publics to the uncertainties hitherto hidden beneath professional mystiques and to the professional errors that inevitably occur in, for example, healthcare and examination systems. Whilst provider league tables may bring strong pressures for improved perform- 
ance, they may simultaneously spread insecurity among both providers and customers/clients. At the level of the individual, improved knowledge of genetic code may not only bring new medical treatments but may render some individuals uninsurable and raise family tensions, for instance in generating pressures to prove biological relationships.

Third, transparency can be counterpoised with accountability: the relationship is strongly argued to contribute to political accountability, though the fact that it can encourage centralism is evidenced by UK policies on higher education, health, and local government. Under the media spotlight, central government politicians and departments pull in powers, whatever the rhetoric about devolution and 'new localism'. Sectoral convergence is taking place between public and private sectors in operational procedures (for example, accounting, human resource management, and operations management), with most of the movement coming from the public sector. Yet 'codes of accountability' remain divergent and their relative emphases contingent (Gray and Jenkins 1993: 62-4). Who should be accountable to whom and for what is disputed in the public sector. This is at the heart of what Gray (1998: 12-13) means by the public sector being 'business-like, but not like a business'. Transparency in the public sector inevitably raises issues about the distribution of power and resources. As well as generating outputs and outcomes, public service providers are expected to demonstrate process values (such as due process, equity, participation, and deliberation).

Nevertheless, experience with private sector accounting regulation and corporate governance indicates that the private sector position is less clear-cut than is often portrayed. Controversy has raged in the United Kingdom about mandatory, as opposed to voluntary, Operating and Financial Reviews in listed company annual reports. ${ }^{1}$ Such developments raise the question of whether disclosure is viewed as a benefit or a cost and, if the latter, as an implied cost of limited liability status or as an implied cost of raising capital on public capital markets. If only the latter, 'going private' affords a mechanism for private firms to deny information to 'outside' shareholders and to stakeholders who are not shareholders (Gamble and Kelly 2000: 42-7). For example, whereas accounting

\footnotetext{
${ }^{1}$ To widespread astonishment, though to the delight of the CBI which had lobbied against mandatory OFRs, the abolition of the mandatory requirement was announced in the December 2005 Pre-Budget. At the time of writing, it is not clear what is going to happen: the Accounting Standards Board has reissued its guidance on OFRs in a different category of pronouncements and many companies may not regard them as 'voluntary'.
} 
standards become more rigorous and better enforced, some quoted companies (such as Littlewoods Stores and DFS) are taken 'private', in part to avoid the transparency associated with listing. Audit developments after US scandals such as Enron, including the US Sarbanes-Oxley Act with its international reach, have imposed substantial transaction costs, thus adding to the 'the costs of being public' (that is, listed on stock markets). Moreover, the institutionalization of share ownership, through intermediaries such as pension funds and hedge funds, have led prominent business leaders to demand transparency on the part of shareholders, in particular with regard to lending and borrowing shares. Large companies appear to be more concerned about trading patterns that (they consider) destabilize their share price than about the transaction costs of meeting the accounting and other regulations attached to listed status (Sunderland 2005: 6-7).

Fourth, transparency can be counterpoised with the set of issues, much discussed in the literature on public organizations and enterprises, that falls under the rubric of autonomy and control. Transparency can be an instrument of external hierarchical control, paradoxically operating in a non-transparent manner, for example, through opportunistic intervention in forms conducive to blame deflection. It may thus allow control to be directed from 'outside' the organization, calling into serious question where organizational boundaries really lie. It may be necessary to look at the system or network of organizations to understand where control lies and thus to define appropriate boundaries (for example, for purposes of accounting consolidation and for accounting for privately financed public assets that are often kept off public sector balance sheets) (Froud and Shaoul 2001: 261-2). The working out of the conflicting tendencies generated by control systems raises complex issues, best pursued on a case-by-case basis. Pressure to perform may stimulate but it may also undermine (Otley 1987: 44-6). Using public money inevitably introduces constraints not present in genuinely competitive private markets (Heald and McLeod 2002: para 483); avoiding those constraints may sometimes constitute an argument against public sector involvement, but in many cases the tensions will have to be managed. Moreover, the role of transparency will vary according to habitat and the style of control (Dunsire 1990: 6-10; Finkelstein 2000: 2-7).

Fifth, transparency can be counterpoised with a set of related but distinct objects, conveniently labelled confidentiality, privacy, and anonymity. In government, confidentiality is in part enduring (though the legal commitment of ministers and civil servants is breached in memoirs), but 
much is a matter of time-confidentiality (for example, about the content of Budgets and Select Committee reports). ${ }^{2}$ The acceptance of confidentiality obligations can be threatened by government spinning that weakens the moral sanctions constraining others. Privacy relates to the affairs of the individual; kiss-and-tell stories in tabloids and proposals to publish the tax returns of the rich (Monbiot 2004) illustrate common confusion between what the public may wish to know and what it has a right to know. ${ }^{3}$ Indeed, a judgment by Lord Woolf (then Lord Chief Justice of England and Wales) concerning tabloid revelations of adultery by a professional footballer, contributed to the blurring of the public interest with what the public is interested to know:

In many of these situations it would be overstating the position to say that there is a public interest in the information being published. It would be more accurate to say that the public have an understandable and so a legitimate interest in being told the information. If this is the situation then it can be appropriately taken into account by a court when deciding on which side of the line a case falls. The courts must not ignore the fact that if newspapers do not publish information which the public are interested in, there will be fewer newspapers published, which will not be in the public interest ( $A$ v. $B \& C$ (2002) EWCA Civ $337){ }^{4}$

Anonymity is an important principle in voting, whether in ballots and elections or in the making of collective decisions that have to be externally defended (such as interviewing committees, examination boards, political group meetings and Cabinet meetings). But anonymity is widely abused in the UK media's coverage of government and politics, with much material unsourced and made available for questionable motives, and such abuses may lead anonymity to be challenged. ${ }^{5}$ Even this limited range of examples shows how difficult it is to strike a balance between

${ }^{2}$ Freedom of information is extensively discussed elsewhere in this volume, especially by Birkinshaw (Chapter 3), Roberts (Chapter 7) and McDonald (Chapter 8).

${ }^{3}$ An indication of the importance of habitat and cultural expectations is provided by the fact that in Finland it is possible to visit the local tax office and find out the amount of income an individual has declared and the amount of central and local taxes paid. However, individuals are identified only by name and year of birth, not by identity card number or home address (information supplied by the National Board of Taxes, Helsinki).

${ }^{4}$ Rozenberg (2004: 14) noted that 'these remarks by Lord Woolf were obiter dicta-incidental observations not material to the case, and therefore not binding on other judges'.

${ }^{5}$ In Chapter 6 below, Andrea Prat discusses differences in attitude to transparency between the Bank of England (minutes and voting records are published a month in arrears) and the European Central Bank (ECB records remain secret for fifteen years); he provides a possible explanation in terms of the Bank of England having a single principal (UK government) and the ECB having multiple principals (i.e. Eurozone member-state governments). 
state, civil society, and the individual; some demands for transparency are intimidatory in effect, even if not in intent. ${ }^{6}$ The private sector counterpart to these issues concerns the release of market-sensitive information, with strong prohibitions against unstructured and non-universal release because of the opportunities for insider trading and false markets. Organizations, public and private, are now more sensitive about their media portrayal, thereby limiting the freedom of speech of those working for them. They have acquired a harder shell, emphasizing employee obligations of confidentiality. Except for those willing to adopt the exposed status of whistleblower, the position is vulnerable; it is intriguing to watch how people clam up or reach for the organizational shield, if asked on the record about their own organizations. ${ }^{7}$ Vulnerability is compounded when there are also doubts about their ability to talk through issues in private within the organization, without fear of opportunistic disclosure at a later stage, for example to undermine those who have subsequently accepted the collective position.

Sixth, transparency can be counterpoised with fairness. This poses fundamental questions about the substantive content of fairness, as distinct from its rhetorical power. For instance, fairness can be conceptualized in terms of rights, deserts, or needs. In political debate, however, fairness is often taken to mean less inequality. The conventional view might be that transparency reduces inequality, concern about unequal rewards leading to tax policy changes and the exposure of abuses prompting correction. On a negative interpretation, transparency might generate envy that damages incentives in the market economy and thus economic performance. During the UK Chancellorship of Gordon Brown (1997 to the time of writing), a counter-view has appeared in media coverage. Polly Toynbee (Guardian journalist) and John Grieve Smith (Cambridge University and occasional Observer commentator) have both defended stealth as an agenda-shifting means to do good by financing poverty reduction. Quite apart from differences in value judgements and perceptions of efficiency-equity trade-offs, the measurement issues relating to the empirical assessment of fairness are formidable. A modern welfare

\footnotetext{
${ }^{6}$ Montagnon (2005a, b) argues against mandatory disclosure of how company shareholders vote their shares, in part on this ground: 'One fear is that mandatory disclosure could lead to unfair pressure on institutions from single-issue campaigners who might have a worthy cause but are themselves unaccountable. A mix of serious campaigners, zealots and eccentric busybodies is undoubtedly already preparing to wade in' (Montagnon 2005b).

7 One element in Power's 'social construction' of the auditee (2003: 200-1) is that 'she hears the rhetoric of excellence in official documents but lives a reality of decline'.
} 
state involves a complex web of subsidies and cross-subsidies, some of which churns across individual lifetimes and some of which is interpersonal and intergenerational (Glennerster 2003: 5-6; Hills 2004: 90-4). Moreover, there can be large differences between expected and actual patterns of redistribution.

Seventh, transparency can be counterpoised with legitimacy. Kay (2002) observed: 'Legitimacy is the answer to the question: "What gives them the right to do that?". 'Legitimacy can be derived from operational mechanisms such as funding formulae being transparent in both their results and numerical working (McLean 2005: 168-76). At the micro-level, it may be possible to predict reasonably accurately university shares of UK government research funding after the 2008 Research Assessment Exercise, without actually undertaking such an exercise (Knight 2004). Nevertheless, without such a process, the legitimacy of dramatically unequal allocations would be much more difficult to defend. This is a separate but related point to the consideration that some form of due process is required before 'historic entitlements' can be withdrawn; a feature of formula funding is its potential to 'abolish the history' that has generated existing allocations. At the macrolevel, the development of international surveillance of national public finances by the International Monetary Fund, World Bank, Organisation for Economic Co-operation and Development, and European Commission, raises issues about the legitimacy as well as effectiveness of upwards transparency. Domestic governmental organizations such as quangos, supranational organizations such as the European Union, and international organizations such as the IMF and the World Bank, that are seen to lack direct democratic credentials, may adopt transparency as a legitimization strategy (Curtin 1998: 107-10). Certain kinds of private organization may do likewise. Although the content is unimpressive, the inaugural Transparency Report of KPMG International (2005), a co-operative registered in Switzerland and run from Amsterdam, demonstrates the importance that this Big 4 financial services firm attaches to reasserting its legitimacy after its US tax scandal. The worst feasible outcome of that scandal would have been the destruction of KPMG, as indeed happened to Arthur Andersen, the erstwhile fifth Big 5 firm, as a direct result of the Enron scandal.

Two polar views might be taken of these seven relationships between transparency and other concepts. Transparency might be seen as a core concern, to be intrinsically valued, or as something to be valued instrumentally, as a building block that underpins the seven intrinsically valued concepts. On that view, transparency is presumed to make a non-negative contribution to each of these 'higher' concepts. 
Alternatively, transparency and the other seven objects might be classified as higher level and lower level. Disciplinary background and ideological disposition are likely to affect an individual author's view of the desirable hierarchy of the eight objects. The present author would rank four (effectiveness; accountability; fairness; and legitimacy, in no particular order) above four (transparency; trust; autonomy and control; and confidentiality, privacy and anonymity, in no particular order). The contention behind this ranking is that the second four are in large part means to the first four. The 'right' varieties of transparency are valued because they are believed to contribute, for example, to effective, accountable, and legitimate government and to promoting fairness in society. Where government is ineffective, unaccountable, and illegitimate, and where society is characterized by unfairness, the researcher can look for evidence of shortfalls in the second group of four. Governments that are corrupt and/or spy on their citizens will not satisfy the first four objects. Although others would certainly disagree with this hierarchy, couching the debate in these explicit terms focuses attention on otherwise obscured trade-offs and synergies.

\section{LIMITS TO TRANSPARENCY}

The seven exercises in counterpoising help to identify not only the benefits of transparency but also how 'limits to transparency' may be required in order to contain resource consumption (both direct and compliance costs) and to ensure that other objectives are met. Three distinct arguments for limiting transparency can be identified.

First, inappropriate varieties of transparency-mostly operational aspects of process, in the terminology of Chapter 2-can impose heavy costs in terms of the achievement of other objectives. For example, inappropriate varieties can impede effectiveness and undermine privacy. As in the case of the Hutton Inquiry's release of government and BBC memoranda and emails (Hutton 2004), ${ }^{8}$ knowledge that private discussions may at some future date be exposed to public ridicule and/or legal process is likely to alter working methods, accentuating the gap between

${ }^{8}$ This inquiry was appointed by the Prime Minister (Tony Blair) following the death of Dr David Kelly, a Ministry of Defence civil servant who had been identified as the source of criticisms of the Government's Iraq war policy that were broadcast on BBC Radio 4's Today programme. 
formal and informal decision-making processes. Similarly, the Railtrack legal case, ${ }^{9}$ in which government emails and memoranda were disclosed in open court, highlights the possibility that the prospect of disclosure may modify working practices in the direction of less record-keeping and less record preservation. The notion that transparency involves every discussion, memorandum, email, and phone call being liable to disclosure is threatening. Another difficulty is that, when accounts of incidents affecting individuals (for example, patients, students, employees, clients and so on) receive media coverage, the continuing obligations of confidentiality owed by the organization may inhibit a frank response (for example, correcting facts and misrepresentations). These circumstances are bound to have significant effects on individual and organizational behaviour, some of which will not enhance efficiency or effectiveness.

Therefore, decision-making space needs to be protected, and the way in which this is done by providers operating under surveillance may impair efficiency and effectiveness. In a parallel literature on transparency in international negotiations between states, there has been considerable attention to the need for negotiating space within which mutually beneficial outcomes can be constructed but whose formulation may involve the sacrifice of public commitments. Whilst all parties may be able to defend the final deal, revelation of negotiating offers, especially those that were not finally required, might undermine support for the deal among the parties' own constituencies.

Second, all varieties of transparency might work against the 'social functions of ignorance', particularly in terms of ignorance sustaining pre-established social orders and preserving social harmony. For example, there are situations in both international and domestic politics when a large amount of ambiguity and fudge about process and expected outcomes may lubricate peace initiatives, whether in Palestine or Northern Ireland. Very little can be said at a general level; attitudes to limiting transparency for such reasons (for example, differentiated messages to Israeli and Palestinian publics, or letting the Irish Republican Army non-transparently dispose of its weaponry) are contingent on specific circumstances.

\footnotetext{
${ }^{9}$ Railtrack plc, the privatized railway infrastructure owner, went into administration on 7 October 2001, a decision in which the Department of Transport and the UK Treasury were involved. Railtrack ple was replaced by Network Rail, a company supported by the UK government but classified to the private sector by the Office for National Statistics. Some shareholders brought a case in the courts for misfeasance by the government, but lost the case (Adams and Tait 2005).
} 
Third, transparency does not mean a free-for-all, in terms of immediate and/or complete satisfaction of demands for governmental information. It certainly does not include spinning by governments or leaking by the disaffected. Allen (2000) noted: 'A vital part of transparency is discipline in the release of information.' Unauthorized disclosure of marketsensitive information will reduce trust in capital markets, in contrast to the beneficial effects of regulated disclosure. Some limits on transparency may afford some protection against centralized political power and/or intrusive media, especially when these have developed close manipulative relationships. Even when the political repercussions of 'exposure' of personal 'scandals' are modest, the capacity to wound and disrupt is significant. Information may centralize power, removing 'space' for 'subordinate' actors and creating the illusion that everything can be settled centrally. Moreover, inappropriately structured arrangements for transparency can result in harassment and game-playing, reflecting organizations' vulnerability to opportunistic behaviour and their defensive responses. The UK media environment does not permit disinterest at the centre of government, which finds itself ridiculed if it is not seen to be 'in charge' of everything. Paradoxically, the media induce the intensification of centralization whilst denouncing existing centralization.

There is sufficient force in these limits to urge caution about claims made for transparency. Specifically, transparency should not be elevated to an intrinsic value. If more transparency of a particular direction or variety would enhance, for example, government effectiveness and accountability, then the case should be made on those grounds. Some of the official enthusiasm of organizations such as the IMF for transparency strikes a discordant note in the light of the past views and practices of such organizations, and indeed in the light of some current practices, such as the process for appointing the IMF Managing Director. In terms of the setting of monetary policy by central banks, Thornton (2003: 478-9) is absolutely explicit that the test of transparency over secrecy is superior effectiveness. If the contingent world has changed, and present circumstances mean that transparency in information release supports policy objectives, the case for transparency can be made on those grounds.

\section{CONCLUSION}

Governments need to construct an effective framework for transparency which combines respect for time sensitivity with maximum feasible 
recourse to event transparency, and is restricted, where appropriate, to only the procedural aspects of process transparency. Such frameworks for transparency will be conditioned by the constitutional framework within which a particular government is located. The work of executive government often has to be done in a context of conflict with the media. This leads to concerns that public organizations might not be able to 'think' and that there will therefore be an inferior consideration of policy options. Moreover, self-protection both against centralizing forces within the public sector, most notably from the core of central government, and against (what is perceived to be) unfair media portrayal, is one reason why public organizations have been developing harder shells, seeking to prevent unauthorized disclosure of information or position-taking by their employees. Institutional weakness not only contributes to policy and implementation failure but also damagingly opens up operational aspects of process. A practical advantage for governments is that proactive disclosure often kills stories, which otherwise feed upon government being portrayed as concealing information.

Technological advances (see Helen Margetts in Chapter 12 of this volume) have clearly reduced the direct costs of transparency, as the incremental costs of making existing documentation available are often minimal. The reduction of logistical obstacles to transparency heightens the importance of determining which directions and varieties of transparency are appropriate for particular organizations and habitats. The indirect costs of transparency are more difficult to assess. When sunlight becomes searchlight it can be uncomfortable and when it becomes torch it may be destructive. Therefore the synergies and trade-offs discussed in this chapter need to be evaluated carefully. This kind of reflection is more likely to occur if it is remembered that transparency should be regarded as an instrumental value.

The beneficial nature of transparency is contingent upon the directions and varieties of transparency that occur and on the habitat with which they interact. This is a much more optimistic conclusion than is reached by Onora O'Neill in Chapter 5, though there are echoes here of some of her concerns. It is vitally important that claims to transparency are tested rather than allowed to go unchallenged, and that the system design issues, particularly about the respective roles of upwards and downwards transparency, are addressed. 


\section{REFERENCES}

Adams, C. and N. Tait. 2005. 'Railtrack High Court judge throws out $£ 150$ m claim brought by 50,000 small shareholders', Financial Times, 15 October.

Allen, W. A. 2000. Speech at the 6th Arab Investment Capital Markets Conference, 18 May, Beirut (http://www.bankofengland.co.uk/publications/speeches/2000/speech 87.htm (accessed 19 March 2006).

Alt, J. and D. D. Lassen. 2006. 'Fiscal Transparency, Political Parties and Debt in OECD Countries', European Economic Review, 50 (forthcoming).

Curtin, D. 1998. 'Democracy, Transparency and Political Participation: Some Progress post-Amsterdam', in V. Deckmyn and I. Thomson (eds), Openness and Transparency in the European Union. Maastricht: European Institute of Public Administration, pp. 107-20.

Dunsire, A. 1990. 'Holistic Governance', Public Policy and Administration, 5(1), 3-18.

Finel, B. I. and K. M. Lord. 1999. 'The Surprising Logic of Transparency', International Studies Quarterly, 43(2), 315-39.

Finkelstein, N. D. 2000. 'Introduction: Transparency in Public Policy', in N. D. Finkelstein (ed.), Transparency in Public Policy: Great Britain and the United States. Basingstoke: Macmillan, pp. 1-9.

Froud, J. and J. Shaoul. 2001. 'Appraising and Evaluating PFI for NHS Hospitals', Financial Accountability \& Management, 17(3), 247-70.

Gamble, A. and G. Kelly. 2000. 'The Politics of the Company', in J. Parkinson, A. Gamble, and G. Kelly (eds), The Political Economy of the Company. Oxford: Hart, pp. $21-49$.

Glennerster, H. 2003. Understanding the Finance of Welfare: What Welfare Costs and How to Pay for It. Bristol: Policy Press.

Glennerster, R. and Y. Shin. 2003. Is Transparency Good for You, and Can the IMF Help? IMF Working Paper WP/03/132, Washington DC, International Monetary Fund.

Gray, A. 1998. Business-Like, But Not Like a Business. London: CIPFA.

Gray, A. and B. Jenkins. 1993. 'Codes of Accountability in the New Public Sector', Accounting, Auditing \& Accountability Journal, 6(3), 52-67.

Heald, D. A. 2003. 'Fiscal Transparency: Concepts, Measurement and UK Practice', Public Administration, 81(4), 723-59.

Heald, D. A. and A. McLeod. 2002. 'Public Expenditure', in The Laws of Scotland. Stair Memorial Encyclopaedia: Constitutional Law Volume. Edinburgh: LexisNexis Butterworths, paras 480-551.

Hills, J. 2004. Inequality and the State. Oxford: Oxford University Press.

Hood, C. 2001. 'Transparency', in P. B. Clarke and J. Foweraker (eds), Encyclopaedia of Democratic Thought. London: Routledge, pp. 700-4.

Hutton, Lord. 2004. Report of the Inquiry into the Circumstances Surrounding the Death of Dr David Kelly CMG, HC 247 of Session 2003-04, London: Stationery Office.

Kay, J. 2002. 'Beware Authority without Legitimacy', Financial Times, 26 September.

Knight, P. 2004. 'Why spend £20m on the Research Assessment Exercise, says Peter Knight. He can tell you the results for free', Times Higher Educational Supplement, 12 October. 
KPMG International. 2005. KPMG's Transparency Report: March 2005. Amsterdam: KPMG International.

Lloyd, J. 2004. What the Media are Doing to Our Politics. London: Constable.

McLean, I. 2005. The Fiscal Crisis of the United Kingdom. Basingstoke: Palgrave Macmillan.

Monbiot, G. 2004. 'Publish and Be Damned', Guardian, 28 September.

Montagnon, P. 2005a. 'Investors should not be forced to disclose their votes', Financial Times, 24 August.

Montagnon, P. 2005b. 'Looking beyond the need for transparency', Financial Times, 31 October.

Moore, W. E. and M. M. Tumin. 1949. 'Some Social Functions of Ignorance', American Sociological Review, 14(6), 787-95.

O’Neill, O. 2002. A Question of Trust. The BBC Reith Lectures, 2002. Cambridge: Cambridge University Press.

Otley, D. 1987. Accounting Control and Organizational Behaviour. London: Heinemann.

Persaud, A. 2000. 'Sending the Herd Off the Cliff Edge: The Disturbing Interaction between Herding and Market-Sensitive Risk Management Practices', E. Risk.com, 1-6 (December), www.erisk.com/ResourceCenter/ERM/persaud.pdf (accessed 29 March 2006).

Power, M. 2003. 'Evaluating the Audit Explosion', Law and Policy, 25(3), 185-202.

Prat, A. 2005. 'The Wrong Kind of Transparency', American Economic Review, 95(3), 862-77.

Rozenberg, J. 2004. Privacy and the Press. Oxford: Oxford University Press.

Sunderland, J. 2005. Speech to Annual Conference of Investor Relations Society, 21 April, Cadbury Schweppes plc.

Thornton, D. L. 2003. 'Monetary Policy Transparency: Transparent About What?', Manchester School, 71(5), 478-97.

Vickers, J. 2002. 'The Hedgehog and the Fox in Economic Policy'. Oxford Business Alumni Lecture, 11 June, on www.oft.gov.uk/NR/rdonlyres/932DC0F2-6E41436A-A4FF-A21E894A543F/0/spe0502.pdf (accessed 19 March 2006). 


\section{Copyright $\odot$ British Academy 2006 - all rights reserved}

